

\section{Sumário}

O USO DE BOTS SOCIAIS COMO AMEAÇA À DEMOCRACIA .............................................................13

Mateus de Oliveira Fornasier

In Memoriam: The Republican Form and the Separation-of-Powers Among the Four

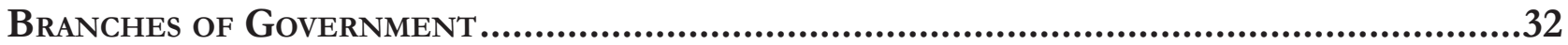

Farris Lee Francis

TODOS E CADA UM DE NÓs: O INTERESSE PÚBLICO COMO CRITÉRIO DE DESENVOLVIMENTO HUMANO

Mártin Haeberlin e Flávio Comim

FACTORES DERIVAdos DE LA POBREZA MULTIDIMENSIONAL QUE AFECTAN LA USABILIDAD DEL e-gobierno en México

Oscar Yahevh Carrera Mora, Luis Fernando Villafuerte e Saulo Sinforoso Martínez

¿Qué ha PASAdo CON Los PRINCIPIOS DE Universalidad, Solidaridad y EFICIENCIA DEL Sistema General de Seguridad Social en Salud de Colombia?

David Mendieta e Carmen Elena

CHANGING THE BENCH FOR A HANDSHAKE: LITIGATION, ADMINISTRATIVE RESOLUTION AND MEDIATION IN FREEDOM OF INFORMATION COMPLAINTS IN CHILE

Pablo Contreras

A evolução identitária da Controladoria-Geral da União: polifonia e decisões em POLÍTICAS DE TRANSPARÊNCIA E ACESSO À INFORMAÇÃO

Érica Bezerra Queiroz Ribeiro e Bruno Amaral Machado

As RAÍZES CRISTÃS DO PRINCÍPIO JURÍDICO DA FRATERNIDADE E AS CRISES MIGRATÓRIAS DO TERCEIRO MILÊNIO.

Maria Celeste Cordeiro Leite dos Santos e Marilene Araujo

JUDICIALIZAÇÃo DESCENTRALIZADA E INDIVIDUALIZADA DA POLÍTICA: MUDANÇAS NAS REGRAS DE tramitação de Medidas Provisórias a partir da Emenda Constitucional 32 155 Leandro Molhano Ribeiro e Mariana Novotny Muniz

O PAPEL DO CNJ DIANTE DO RECONHECIMENTO DO ESTADO DE COISAS INCONSTITUCIONAL DO SISTEMA CARCERÁRIO BRASILEIRO NA PERSPECTIVA DO ATIVISMO DIALÓGICO. 176 Ana Paula Kosak e Estefânia Maria de Queiroz Barboza 
Efeitos do Programa Mais Médicos (PMM) nos resultados da Atenção Básica À SAÚDE.

Alex dos Santos Macedo e Marco Aurélio Marques Ferreira

OrÇamento para os direitos das CRianÇas E adolescentes EM CuRitiba: Plano E EXECUÇÃO

Karoline Strapasson Jambersi e Antonio Gonçalves de Oliveira

A Capacidade do Estado frente a gestão de riscos e desastres após a Política Nacional de Proteção e Defesa Civil (Lei 12.608/2012) .............................................245

Larissa Maria da Silva Ferentz e Carlos Mello Garcias

REFunCIONALIZAÇÃo da PENA DE PRISÃo: ABORDAGEM ACERCA DA ALIENAÇÃo DO TRABALHO

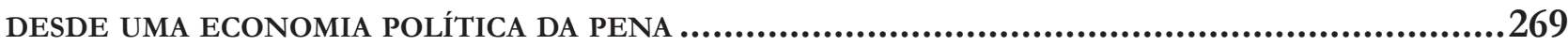
Jackson da Silva Leal

LA CONSTITUCIONALIZACIÓN DEL DERECHO A DEFENSA JURIDICA DE LAS VICTIMAS EN CHILE 286 Marcela Peredo Rojas

COLABORAÇÃo PREMIADA E SELETIVIDADE DO SISTEMA PENAL: PROBLEMATIZAÇõES ACERCA DA UTILIZAÇÃo de aCordos Na Operação LaVa Jato

Maiquel Ângelo Dezordi Wermuth e Maurício Habckost Dalla Zen

Poder, MASCULINIDAde E PARTICIPAÇão EM FaCções CRIMINOSAS A PARTIR DE RELATOS ADOLESCENTES PRIVADOS DE LIBERDADE PELA PRÁTICA DE ATOS INFRACIONAIS

Jailson Alves Nogueira, Ramon Rebouças Nolasco de Oliveira, Lauro Gurgel de Brito e Veruska Sayonara de Góis

MobILIZAÇÃo JURÍDICA E O DIREITO AO ABORTO NO BRASIL: A EVOLUÇão ARGUMENTATIVA NAS RESPECTIVAS AÇÕES DE CONTROLE CONCENTRADO DE CONSTITUCIONALIDADE .355

Fabiano Hartmann Peixoto e Thales Alessandro Dias Pereira 


\title{
Poder, masculinidade e participação em facções criminosas a partir de relatos adolescentes privados de liberdade pela prática de atos infracionais*
}

\author{
Power, masculinity and participation in \\ criminal factions from teenagers private of \\ freedom by the practice of infringement acts \\ reports
}

\author{
Jailson Alves Nogueira** \\ Ramon Rebouças Nolasco de Oliveira*** \\ Lauro Gurgel de Brito**** \\ Veruska Sayonara de Góis*****
}

* Recebido em 07/01/2020

Aprovado em 13/03/2020

** Mestrando em Ciências Sociais e Humanas
e graduado em Direito pela Universidade do
Estado do Rio Grande do Norte (UERN). E-
mail: jailsonalvesuern@hotmail.com.

*** Doutor em Direito pela Universidade de Brasília (UnB), mestre em Ciências Sociais e Humanas, especialista em Direitos Humanos e graduado em Direito pela Universidade do Estado do Rio Grande do Norte (UERN). Professor da Universidade Federal Rural do SemiÁrido (UFERSA). Advogado.

E-mail: ramonreboucas@gmail.com.

**** Doutor em Direito pela Universidade de Brasília (UnB), mestre em Direito pela Universidade Federal do Rio Grande do Norte (UFRN), graduado em Direito pela Universidade do Estado do Rio Grande do Norte (UERN). Professor da Universidade do Estado do Rio Grande do Norte (UERN).

E-mail: laurogurgel@uern.br.

***** Mestra em Direito pela Universidade Federal do Rio Grande do Norte (UFRN), graduada em Direito pela Universidade do Estado do Rio Grande do Norte (UERN) e graduada em Comunicação Social pela Universidade Federal do Rio Grande do Norte (UFRN). Professora da Universidade do Estado do Rio Grande do Norte (UERN). E-mail: veruskasayonara@gmail.com.

\section{Resumo}

O artigo investiga as relações de poder e a masculinidade num cenário de prática de atos infracionais e de participação em facções criminosas. Trata-se de um trabalho de cunho teórico e empírico que, além da revisão bibliográfica, explora dados produzidos pelo Projeto de Extensão Direitos Humanos na Prática, da Universidade Federal Rural do Semiárido (UFERSA), no primeiro semestre de 2018. A partir de 3 (três) instrumentos de coletas com informações sobre "poder" e "masculinidade" dos adolescentes, são analisados os relatos de adolescentes internados no Centro de Atendimento Socioeducativo Mossoró/RN (CASE). Podemos concluir que a vontade de poder e a necessidade de afirmação da masculinidade dos adolescentes atuam de modo a contribuir para a prática de atos infracionais e a participação em facções criminosas.

Palavras-chave: Adolescentes. Ato infracional. Facções criminosas. Masculinidade. Poder.

\section{Abstract}

The study investigates the relations of power and masculinity in a scenario of programs for young offenders and participation in criminal factions. This theoretical and empirical work explores data produced by the Human Rights in Practice University Extension Project, of the Universidade Federal Rural do Semi-Árido (UFERSA), in the first half of 2018. From 3 (three) collection instruments with information on "power" and "masculinity" of teenagers, the reports of teenagers in custody at the Socio-Educational Assistance Center (CASE) from Mossoró/RN are analyzed. We can conclude that the desire for power and the need to affirm the masculinity of teenagers 
act in order to contribute to the commission of infringement acts and participation in criminal factions.

Keywords: Teenagers. Infringement Act. Criminal factions. Masculinity. Power.

\section{Introdução}

Após germinarem-se, fixarem-se e dominarem o sistema penitenciário brasileiro, as facções criminosas têm expandido seu campo de atuação nos últimos anos, tanto dentro quanto fora do país ${ }^{1}$. Inicialmente, desenvolvendo atividades ilícitas na Região Sudeste, sobretudo nos estados do Rio de Janeiro e São Paulo, esses grupos viram, na Região Nordeste, um campo fértil a ser explorado. Tanto o sistema penitenciário quanto o sistema socioeducativo potiguar estão inseridos nesse contexto de expansão da criminalidade.

A participação de adolescentes em facções criminosas e a prática de atos infracionais se relacionam com fatores que tangenciam o biopsicossocial, dentre eles o poder e a masculinidade. Esses dois fatores emergem e dialogam entre si como características de dominação sobre o outro, seja demonstrando virilidades ao "dispor" das mulheres mais bonitas (masculinidade), ou por meio de instrumentos que potencializam a sobreposição de um sujeito pelo outro, como a utilização de armas de fogo (poder).

Diante disso, o presente artigo tem como objetivo analisar, teórica e empiricamente, o poder e a masculinidade num cenário de prática de atos infracionais e da participação de adolescentes em facções criminosas. A abordagem teórica é feita a partir de uma revisão bibliográfica. Já no campo empírico, o artigo explora o banco de dados do Projeto de Extensão Direitos Humanos na Prática, da Universidade Federal Rural do Semiárido (UFERSA), do qual selecionamos três instrumentos de coletas que continham informações acerca da temática abordada ${ }^{2}$. Os relatos são de adolescentes que cumpriam medida socioeducativa de internação no Centro de Atendimento Socioeducativo Mossoró/RN (CASE) no primeiro semestre de 2018.

A análise teórica e empírica nos possibilitou concluir que tanto a vontade de poder quanto a necessidade de afirmação da masculinidade dos adolescentes atuam no sentido contribuir para a prática de atos infracionais e a participação em facções criminosas, oportunizando reconhecimento social de adolescentes em vulnerabilidade socioeconômica, mesmo que seja pela via das práticas ilícitas.

Para chagarmos a esse resultado, dividimos o trabalho em duas partes. Num primeiro momento, abordamos de que forma o poder e/ou a vontade de tê-lo ou de expressá-lo contribuem para a prática de atos infracionais e para a participação de adolescentes em grupos criminosos, e, posteriormente, analisamos como a dimensão da masculinidade dos adolescentes, enquanto sentimento de virilidade, dialoga com seus comportamentos ilícitos e facciosos.

\section{Adolescência e vontade de poder}

Apesar das relações de poder serem debatidas preponderantemente no campo da política e da economia, elas possuem uma estreita relação com as práticas ilícitas, sobretudo quando envolvem a participação de adolescentes em facções criminosas. Com isso, fica evidente a indissociabilidade entre as expressões jurídi-

\footnotetext{
1 MANSO, Bruno Paes; DIAS, Camila Nunes. A guerra: a ascensão do PCC e o mundo do crime no Brasil. 1. ed. São Paulo: Todavia, 2018.

2 Importante destacarmos que os demais instrumentos (que foram no total de seis), não incluídos na análise, não negaram os fatores do "poder" e da "masculinidade", todavia, alguns adolescentes somente tangenciaram essas questões, não ofertando materiais de análise suficientemente adequados. Apesar do Centro de Atendimento Socioeducativo Mossoró (CASE) ter capacidade para alojar 48 adolescentes do sexo masculino, no momento da coleta dos dados estava com sua capacidade reduzida a 30 adolescentes, já que, devido às suas condições estruturais, encontrava-se sob intervenção judicial.
} 
cas e os fenômenos da política e da economia. É importante compreendermos o poder além das obviedades políticas e econômicas. Ele é intrínseco à pessoa e às relações humanas. Está na família, no trabalho e até mesmo no saber, a partir do qual queremos encontrar uma verdade para se buscar o poder ${ }^{3}$, ou a vontade de poder se transveste por pretensa investigação da verdade.

O ser humano tem carências e "o poder desenvolver-se-á, assim, como a possibilidade de mover-se, agir e constituir uma atividade orientada no meio, capaz de satisfazer as exigências das condições de vida do próprio ser"4. Todo sujeito almeja o poder para desenvolver suas atividades cotidianas, algo que não é diferente em relação aos adolescentes em contextos de vulnerabilidades.

Algo bastante problemático é quando os adolescentes, sujeitos em peculiar estágio de desenvolvimento, efetivam ou recorrem ao poder por meio de atividades ilícitas, participando de facções criminosas, as quais se apoiam no poderio bélico e financeiro para se consolidarem. Essa manifestação de poder, muitas vezes exercido pela via das armas de fogo, traz significados para a vida dos adolescentes, ainda que eles sejam caracterizados com "em conflito com a lei" do Estado. É que, sem o acesso a esses instrumentos de poder, podem perder representatividade grupal e saírem fragilizados na teia das relações de poder em que estão inseridos, sobretudo, no ambiente comunitário. A arma não empodera e (re)significa apenas a vida de adolescentes, ela também se difunde entre os adultos como instrumento de legitimidade e autoridade, em menor ou maior intensidade, a depender do contexto e do que está em jogo no "mundo do crime". A utilização de armas de fogo ainda pode ser vista como uma prerrogativa de determinados "irmãos", uma vez que portá-la gera o poder de decidir sobre quem vai viver ou morrer, dentro ou fora do cárcere ${ }^{6}$.

Ao entrarmos em contato com relatos de adolescentes internados no CASE Mossoró, pudemos compreender melhor como se desenvolvem esses mecanismos de poder e significação, que afetam a produção da subjetividade desse grupo social. Num dos relatos extraímos o seguinte: "o que me fez entrar para a facção criminosa foi o poder de fogo que ela dispõe, o maior do RN, e a maconha. Isso me faz sentir bem e poderoso". E mais: “o desejo de pertencer a um grupo foi o que me fez participar de facção, lá tem união, coletividade, respeito e cumplicidade" .

Outro adolescente relata que sempre recebe convites dos seus colegas para fazer parte de grupos facciosos, mas vem se negando. De acordo com ele, seus colegas se utilizam da atratividade que a arma de fogo proporciona para recrutar novos adolescentes: "meus colegas me chamam pra fazer parte das facções, diz que é bom porque têm armas, mas não vou" ${ }^{8}$. Em ambas as narrativas, o poder que a arma de fogo proporciona foi utilizado como elemento de sedução dos jovens. No começo para atraí-los; depois, para fixá-los nos grupos faccionais.

Diante de tais promessas, ainda que elas possam ser ilusórias e passageiras, os adolescentes parecem encontrar, no seio das facções criminosas, a aquisição de poder, a satisfação dessa vontade humana de ser empoderado ou, pelo menos, o sentimento de ser capaz de sobrepor o outro. Assim, constrói-se a ideia de pertencimento a um grupo que atende também à sua demanda por reconhecimento e identidade, certo status social negado por outras esferas, como a família, instituições públicas (escola, hospitais, polícias) e diversos espaços sociais (shoppings, praças, etc.). Portanto, fortalece neles a crença de que, quanto mais tiverem aces-

3 FOUCAULT, Michel. Microfísica do Poder. Organização e tradução de Roberto Machado. 18. ed. Rio de Janeiro: Edições Graal, 1979.

4 MARINO FILHO, Armando. A Necessidade da Educação do Poder e do Domínio para as Relações Sociais e Políticas. Rev. Psicol. Polit., São Paulo, v. 10, n. 20, dez. 2010. p. 265. Disponível em: http://pepsic.bvsalud.org/scielo.php?script=sci_arttext\&pid=S1519549X2010000200006. Acesso em: 12 set. 2019.

5 FELTRAN, Gabriel Santis. Crime e Castigo na Cidade: os repertórios da justiça e a questão do homicídio nas periferias de São Paulo. Caderno CRH, Salvador, v. 23, n. 58, p. 59-73, jan./abr. 2010. Disponível em: http://www.scielo.br/pdf/ccrh/v23n58/ v23n58a05.pdf. Acesso em: 05 mar. 2020.

DIAS, Camila Caldeira Nunes. PCC: hegemonia nas prisões e monopólio da violência. São Paulo: Saraiva, 2013.

Adolescente 01, 17 anos.

Adolescente 02, 17 anos. 
so a armas de fogo, mais poderão dominar seus inimigos e ganhar respeito e pertencimento comunitário/ carcerário/socioeducativo pela via das práticas ilícitas, principalmente, perante as facções criminosas rivais e o Estado, representado pelos agentes de segurança.

Quando falamos em socioeducação, criminalidade e sistema penitenciário, notamos que vêm à tona também as vulnerabilidades dos agentes das forças de segurança, num processo de (des)humanização dos sujeitos diretamente envolvidos nesses conflitos. Tudo isso está imbricado com os "micropoderes" nos ambientes de restrição de liberdade, provenientes tanto de quem cumpre a medida/pena quanto dos agentes que trabalham nas unidades onde o Estado mantém o controle. Em verdade, há uma relação simbiótica entre eles (Estado e facções criminosas), uma permissão informal. Num cenário igual a esse, o poder estatal “não se aplica pura e simplesmente como uma obrigação ou uma proibição, aos que 'não têm'; ele os investe, passa por eles e por meio deles, apoia-se neles".

O poder não pode ser visto como um instrumento que é dado naturalmente, pois existem outros fatores que se comunicam. Na relação de poder entre adolescência e facções criminosas, ele não existe somente por uma carência biológica, mas se expressa sócioculturalmente. Por outro lado, ele também não se impõe única e unilateralmente, precisa ser articulado,

[...] o que significa que essas relações se aprofundam dentro da sociedade, que não se localizam nas relações do Estado com os cidadãos ou na fronteira das classes e que não se contentam em reproduzir ao nível dos indivíduos, dos corpos, dos gestos e dos comportamentos a forma geral da lei ou do governo; que se há continuidade (realmente elas se articulam bem, nessa forma, de acordo com toda uma série de complexas engrenagens), não há analogia nem homologia, mas especificidade do mecanismo e de modalidade ${ }^{10}$.

Essas relações de poderes são singulares, não obedecem à lógica binária do "sim ou não", como se um elemento tivesse poder e o outro não, com uma suposta “soma zero". É preciso levarmos em consideração as pluralidades que contornam o poder, como as vulnerabilidades dos sujeitos dentro e fora do seu contexto de convivência familiar e comunitária. Nesse sentido, quando essa convivência não se processa de maneira saudável e positiva, ainda que as crises sejam próprias do desenvolvimento humano e social, como oportunidades de criação e afirmação da personalidade do sujeito, as vulnerabilidades e carências se configuram como excelentes "janelas de oportunidade" para as facções criminosas oferecerem sentido à vida dos adolescentes. Isso implica a possibilidade de crescimento e satisfação pessoal, ainda que por meio das atividades ilícitas.

O poder costuma ser visualizado a partir de um lócus centralizador, o Estado. Do mesmo modo, o Direito é, habitualmente, visto na sua concepção monista, de jurisdição e legiferação exclusivamente estatais. Todavia, esses pretensos dogmas de teorias políticas e jurídicas não correspondem ao olhar sociológico mais realista, que enxerga um tipo de pluralismo normativo/jurídico, haja vista a nítida presença de códigos normativos/jurídicos no interior das facções criminosas, ainda que a normatividade não seja legítima ou se configurem antinomias entre o direito estatal e o "direito faccional"1.

Há um pluralismo de poderes dentro do contexto em que estão envolvidos Estado e facções criminosas. Poderíamos falar de "micropoderes"12, que constituem o desenvolvimento de uma luta em volta de um foco particular de poder. Esses focos são capazes de criar inúmeros pequenos focos, que podem "ser um pequeno chefe, um guarda de H. L.M., um diretor de prisão, um juiz, um responsável sindical, um redator-chefe de um jornal”'13.

9 FOUCAULT, Michel. Vigiar e punir: nascimento da prisão. Tradução de Raquel Ramalhete. 42. ed. Petrópolis: Vozes, 2014 . p. 30. 10 FOUCAULT, Michel. Vigiar e punir: nascimento da prisão. Tradução de Raquel Ramalhete. 42. ed. Petrópolis: Vozes, 2014. p. 30.

11 OLIVEIRA, Ramon Rebouças Nolasco de; NOGUEIRA, Jailson Alves. O Intrincamento entre os Códigos Jurídicos do Estado de Direito e das Facções Criminosas. Meritum, Belo Horizonte, v. 14, n. 1, p. 413-428, jan./jun. 2019. Disponível em: http://www. fumec.br/revistas/meritum/article/view/6592/pdf. Acesso em: 06 out. 2019.

12 FOUCAULT, Michel. Vigiar e punir: nascimento da prisão. Tradução de Raquel Ramalhete. 42. ed. Petrópolis: Vozes, 2014.

13 FOUCAULT, Michel. Microfísica do Poder. Organização e tradução de Roberto Machado. 18. ed. Rio de Janeiro: Edições Graal, 1979. 
Apesar dessa análise de Foucault sobre o poder, ele não apresenta uma definição conceitual por acreditar que o poder se trata de um fenômeno complexo e descontínuo. Com isso, não existe um objeto "poder", mas relações de poder dentro de um campo social. E é, nesse sentido, que existe a busca pelo exercício do poder dos adolescentes com intermédio das facções criminosas. É válido salientar que o conceito de poder foi explorado também por vários pensadores, a exemplo dos contratualistas Thomas Hobbes, John Locke e Jean-Jacques Rousseau, e também por Max Weber ${ }^{14}$, os quais influenciaram o surgimento do Estado Moderno ${ }^{15}$.

Algumas comunidades se tornam territórios dominados por facções criminosas, sobretudo nas periferias materialmente empobrecidas das grandes cidades. Nesse cenário, o poder também é expressado e imposto por grupos facciosos e pelo Estado, intercruzando entre si, de modo que, muitas vezes, não é possível a identificação de quem está exercendo e com base em qual código normativo (estatal ou faccioso), pois se modifica a depender do local e do momento, ensejando em relações de poderes. Como exemplo, podemos citar os repertórios da justiça nas periferias de São Paulo, num contexto de imposição das regras do Primeiro Comando da Capital (PCC), que, além da justiça estatal, divina e dos meios de comunicação, o PCC é legitimado como um zelador da lei ${ }^{16}$, atuando como uma instituição extraoficial e com códigos próprios.

Também é importante mencionarmos que há outros centros de poderes que concorrem com o Estado, como o político, o econômico e o religioso ${ }^{17}$. Mas, neste artigo, não iremos nos debruçar sobre essas outras manifestações. Nosso foco é no poder e nas práticas ilícitas que envolvem a participação de adolescentes em facções criminosas, a partir dos próprios relatos de alguns jovens em cumprimento de medida socioeducativa de internação no CASE Mossoró/RN.

Se por um lado a descentralização e abertura do poder fortalece o regime democrático de um Estado, ao inserir grupos marginalizados socialmente nas tomadas de decisões (como é o caso dos adolescentes que habitam as periferias empobrecidas materialmente e estão em maior grau de vulnerabilidade), por outro, pode torná-lo vulnerável e possibilitar o surgimento de grupos que não convergem com a democracia, como é o caso das facções criminosas.

Esses grupos buscam se legitimar, inclusive, pelo viés da criminalidade e da violência, por meio do discurso de resistência ao processo de desumanização sofrido dentro dos ambientes prisionais/socioeducativos. Esse aspecto está ligado à gênese das facções no Brasil ${ }^{18}$. No ambiente comunitário, externo aos espaços de privação de liberdade, as facções têm se expandido ao fornecerem bens e serviços em territórios marginalizados e precariamente assistidos pelo Poder Público. Essas circunstâncias entrelaçam adolescentes, facções criminosas e o Estado em relações de poder muito complexas. Mesmo agindo à margem da legalida-

\footnotetext{
14 O fenômeno das facções criminosas também pode ser visto à luz do pluralismo jurídico e da Sociologia Weberiana, sobretudo quanto aos tipos de dominação propostas por Max Weber. Assim, predomina nesses grupos facciosos a dominação que Weber conceitua como burocrática ou racional-legal, aquela que "não está restrita à lei formalmente positivada, mas se manifesta também nas relações em que os dominados obedecem a ordenamentos 'informais' por eles criados - nesse caso, aos ordenamentos jurídicos das facções" (SILVA; SOUSA, 2018, s. p.). Como proposta de tipos-ideais, essa classificação de Weber não pretende enquadrar todos os aspectos de uma dada forma de dominação concreta, razão pela qual não se descarta também o apelo à dominação "carismática" de alguns líderes (anti-heróis exemplares) perante a comunidade, criando devoção ao líder e laços afetivos entre os "irmãos" da facção. Como as facções têm investido mais em horizontalidade, pela força das complexas circunstâncias, o poder hierarquizado tem amenizado a representação de figuras que poderiam exercer o poder de chefes da organização nos moldes da dominação "tradicional", pelo que prevalece mesmo a dominação "burocrático-legal", que se sustenta pelas hierarquias funcionais e desempenhos em obedecer aos documentos oficiais.

15 SANTIN, Janaína Rigo; MARCANTE, Sheron. Microfísica do poder e poder local. Revista Brasileira de História \& Ciências Sociais, v. 6, n. 11, jul. 2014. Disponível em: https://www.rbhcs.com/rbhcs/article/view/207. Acesso em: 27 nov. 2019.

16 FELTRAN, Gabriel Santis. Crime e Castigo na Cidade: os repertórios da justiça e a questão do homicídio nas periferias de São Paulo. Caderno CRH, Salvador, v. 23, n. 58, p. 59-73, jan./abr. 2010. Disponível em: http://www.scielo.br/pdf/ccrh/v23n58/ v23n58a05.pdf. Acesso em: 05 mar. 2020.

17 SANTIN, Janaína Rigo; MARCANTE, Sheron. Microfísica do poder e poder local. Revista Brasileira de História \& Ciências Sociais, v. 6, n. 11, jul. 2014. Disponível em: https://www.rbhcs.com/rbhcs/article/view/207. Acesso em: 27 nov. 2019.

18 AMORIN, Carlos. CV -PCC: a irmandade do crime. Rio de Janeiro: Record, 2003.
} 
de, as facções criminosas vêm encontrando espaço para manifestarem seu poder e menosprezarem o poder oficial, ganhando adesão e simpatia de pessoas. Sobretudo daquelas que têm os direitos básicos violados pelos próprios agentes do Estado ou que criticam a negligência deste em prover o mínimo necessário a uma vida digna.

Historicamente, crianças e adolescentes são vistos como sujeitos insignificantes, seja no plano internacional ou nacional. Num primeiro momento, entre os séculos XVI e XIX eram vistos como pessoas sem relevância e, consequentemente, sem direitos. A partir do século XX, deixaram de ser concebidos como "animais" e entraram no rol de "objetos" a serem tutelados pelo Estado. Com a promulgação de 1988 e, posteriormente, com o Estatuto da Criança e do Adolescente (1990), crianças e adolescentes passam a ser vistos como sujeitos de direitos, tendo a família, sociedade e Estado obrigação de lhes efetivar os direitos ${ }^{19}$.

Os adolescentes que possuem alguma relação com facções criminosas buscam sabotar quem os sabotam, ou seja, o Estado - por meio dos agentes de segurança - e as facções criminosas rivais, conforme relato de um deles: "os maiores inimigos do [facção A] é os 'puliça' e os [facção B]. Os [facção B] cola com 'puliça" 20. Nesse relato, a identificação de inimigos (fação rival e polícia) fortalece o senso grupal e, de certa maneira, indica como "colar com 'puliça" pode ser uma forma de denunciar que alguns agentes estatais também são cooptados ou se confundem com as facções, num verdadeiro mecanismo de deslegitimação do poder oficial.

Nas facções criminosas, predomina uma relação de poder local, num espaço limitado, mas com reflexo mais amplo, até global. As tomadas de decisões estão mais próximas dos que compõem esses grupos, gerando um sentimento de pertencimento no processo decisório das ações. Nesse mesmo sentido, Camila Caldeira Nunes Dias, ao analisar a figuração da facção criminosa Primeiro Comando da Capital (PCC), arremata que, na nova ordem social da facção, a violência física deixou de ser um instrumento de afirmação e de pertença. Passam a valer mais a posse de bens, o domínio das relações e o pertencimento à facção ${ }^{21}$.

Com esse poder, elas são capazes de realizar ações que, nas comunidades vulneráveis, suprem ou se confundem com "políticas públicas", ao efetivar direitos juntamente aos respectivos membros. Em regra, isso acontece com o apoio das comunidades, seja pelo medo de represália e/ou pela carência material nesses ambientes, como a atuação para garantir o direito à segurança ${ }^{22}$ e o controle nos preços de produtos ${ }^{23}$.

Entretanto, em que pese a retórica do poder das facções, não nos parece crível que esse comportamento das facções e suas demandas por justiça contribuam para uma (r)evolução social e uma mudança dos paradigmas em busca dos sentimentos de justiça, igualdade e democracia, pois o que abastece e sustenta o discurso é a expansão dos negócios ilícitos e a cristalização de práticas ilegais.

É urgente reconhecer que há poderes fora do Estado, entre eles, os que são exercidos pelas facções criminosas perante seus membros e dentro das comunidades onde o poder estatal não atua de modo eficiente ou não são visto como positivo perante o corpo social periférico. Reconhecer a expressão de poder das facções não representa uma diminuição do poder oficial ou um rebaixamento da sua atuação, mas a admissão de um problema concreto relacionado à criminalidade e que exige posturas estatais ativas e inovadoras, com inteligência e uso de tecnologias no combate ao crime e à violência, de sorte que as pessoas voltem a confiar no Estado democrático de Direito.

\footnotetext{
19 Lima, Renata Mantovani de; POLI, Leonardo Macedo; JOSÉ, Fernanda São. A Evolução Histórica dos Direitos da Criança e do Adolescente: da insignificância jurídica e social ao reconhecimento de direitos e garantias fundamentais. Rev. Bras. Polít. Públicas (Online), Brasília, v. 7, n. 2, p. 313-329, 2017. Disponível em: https://www.publicacoesacademicas.uniceub.br/RBPP/article/ view/4796/pdf. Acesso em: 05 mar. 2020.

20 Adolescente 01, 17 anos.

21 DIAS, Camila Caldeira Nunes. PCC: hegemonia nas prisões e monopólio da violência. São Paulo: Saraiva, 2013.

22 SUPOSTA facção criminosa promete punir bandidos em Santa Cruz. Agora RN. Disponível em: http://agorarn.com.br/regionais/suposta-faccao-criminosa-promete-punir-bandidos-em-santa-cruz/. Acesso em: 20 jul. 2019.

23 TRÁFICO espalha cartazes anunciando queda no preço do botijão de gás na rocinha. Extra. Disponível em: https://extra. globo.com/casos-de-policia/trafico-espalha-cartazes-anunciando-queda-no-preco-do-botijao-de-gas-na-rocinha-21893233.html. Acesso em: 28 nov. 2019.
} 
Portanto, é preciso que os agentes do Estado se valham de políticas de segurança e outras políticas públicas (educação, saúde, alimentação, habitação, esporte, lazer, etc.) que supram as necessidades e vulnerabilidades dos cidadãos imersos em ambiente aliciados pelas facções, que investem no empoderamento e pertencimento dos seus membros e, em se tratando de adolescentes homens, na virilidade/masculinidade. A técnica de ampliar o uso da violência física nas comunidades periféricas e a estratégia de encarcerar os sujeitos em condições precárias de cumprimento da pena têm se evidenciado muito onerosas, tanto na dimensão financeira quanto em termos de mortes de policiais, de acusados e de terceiros. Essas escolhas fornecem mais subsídios argumentativos e fáticos para ampliar o poderio das facções.

O poder não pode ser concebido, simplesmente, a partir da utilização da força, mas ela está presente em grande parte das relações e expressões de poder. Hannah Arendt, com um viés mais político do que criminológico, aborda o poder e defende que a violência deve ser dissociada dele porque "se a essência do poder é a efetividade do domínio, não existe então nenhum poder maior do que aquele que provém do cano de uma arma, e seria difícil dizer 'de que maneira a ordem dada por um policial é diferente daquela dada por um bandido armado" "24. Pelo contrário, acreditamos que o poder se expressa a partir de um agir conjunto. Ele pode até ser associado à violência, porque:

[...] es cierto que el poder es a menudo violento y que muchos grupos y personís basan su poder social en su capacidad para hacer violencia a los demás. Pero aunque la capacidad de violencia suponga un poder real, no todo poder es violento ${ }^{25}$.

Compartilhamos da ideia de que as facções criminosas, isoladamente, não dispõem de poderes, mas que há múltiplas relações de poder dentro da sociedade que as fazem se expressar. O poder se manifesta, essencialmente, de forma repressiva, já que "o poder é guerra, guerra prolongada por outros meios"2627, mas, só há poder se houver liberdade ${ }^{28}$.

Nesse sentido, acreditamos que, por meio das armas, os adolescentes, influenciados por facções criminosas, portando uma arma de fogo, possuem, efetivamente, poderes, mesmo que seja momentaneamente "emprestados" da arma. Há, com isso, uma relação de poder entre facções criminosas, sociedade, Estado e facções criminosas rivais, instrumentalizada pelas armas de fogo, como símbolos sociais de empoderamento.

De acordo com o adolescente 03, o sentimento de poder, ora implícita, ora explicitamente, contribuiu para a sua participação em facção criminosa: "a facção pergunta se tamo precisando de alguma coisa: fuga, armas, apoio. Eles desce uma pistola, [escopeta calibre] 12, qualquer coisa que você quiser fazer ela [facção B] ajuda". Ao participarem de facções, os adolescentes passam a se enxergarem sujeitos que carregam características de anti-herói, que nada mais é do que um herói especial, alguém que atua à margem da lei e teve seus direitos negados.

Relatando-nos em outro momento, ele é ciente que o simples fato de portar uma arma de fogo não o torna um sujeito de poder (o poder transita nas relações e a arma produz efeitos de poder), pois o que acontece são expressões das relações de poder de forma transitória, potencializadas pelo sentimento de coletividade presente nos espaços facciosos.

O [facção B] desce armamento e drogas pra gente. Eu sei que o poderoso é o lá de cima, mas a gente também se sente poderoso porque sabe que ninguém vai mexer com nós, a gente pode contar com a

\footnotetext{
24 ARENDT, Hannah. Da violência. Brasília: Ed. Universidade de Brasília, 1985. p. 23.

25 MARTÍN-BARÓ, Ignacio. Sistema, grupo y poder: psicología social desde centroamérica II. El Salvador: UCA Editores, 1989. Colección Textos Universitarios, v. 10.

26 FOUCAULT, Michel. Microfísica do Poder. Organização e tradução de Roberto Machado. 18. ed. Rio de Janeiro: Edições Graal, 1979. p. 99.

27 Buscando compreender o poder a partir de uma concepção política, Foucault inverte o aforismo de Carl von Clausewitz. Este assegura que a guerra nada mais era do que a continuação da política. Já Foucault, pondera que "a política é a guerra prolongada por outros meios".

28 FOUCAULT, Michel. O sujeito e o poder. In: DREYFUS, L.; RABINOW, P. Michel Foucault: uma trajetória filosófica: para além do estruturalismo e da hermenêutica. 2. ed. Rio de Janeiro: Forense Universitária, 2009.
} 
facção. Quando eu sair daqui [CASE], já tem um revólver e uma pistola. O bom, também, é que sempre tá o "mói", todo mundo junto, nunca tá pouco, sempre todo mundo armado 29 .

É notório que o adolescente entrevistado possui uma estreita relação com a facção B. As vulnerabilidades, associadas à sensação de poder que a facção proporciona por meio do acesso a armas de fogo, influenciaram o adolescente a fazer parte do grupo. Soma-se a isso a representatividade social que os bens materiais proporcionam, mesmo sendo resultado de práticas ilícitas.

Diante desse contexto, as facções criminosas solidarizam-se e dão significados ao seu comportamento antissocial, afinal, "o anti-herói ferido pode ser um cavaleiro heroico numa armadura enferrujada, um solitário que rejeitou a sociedade ou foi rejeitado por ela" ${ }^{30}$. Ainda, a invisibilidade social desses sujeitos contribui para que eles busquem, pela via da criminalidade, conseguir representatividade comunitária, o que não lhes parece ser possível pelo viés da legalidade. Vencer, seguindo as leis, pode parecer quimérico e utópico, além de poder soar como uma afronta aos seus pares da comunidade, que sofrem violações e negligências dos "homens da lei".

Mas não se restringe a isso. Há outros fatores relevantes a serem considerados, como no caso de:

[...] una familia desunida, material o emocionalmente insatisfactoria para sus miembros, un ambiente poco acogedor, un indebido aprendizaje temprano, pueden contribuir a formar una personalidad proclive a comportamientos delincuenciales ${ }^{31}$.

O poder que os adolescentes buscam, ao integrarem facções criminosas, é o de submeter e controlar a vontade de pessoas ou grupos, parceiros ou inimigos, sujeitando-os a um código jurídico próprio da facção em que o principal instrumento de coerção é a violência. Eles veem, no poder, a possibilidade de buscar participação nas tomadas de decisões do grupo e reconhecimento perante seus pares, bem como conseguir respeito dentro das associações e comunidades que frequentam.

\section{Masculinidade: sentimento de virilidade, força e poder}

Nos últimos anos, a taxa de mortalidade dos homens jovens ${ }^{32}$ vem aumentando. E não há nenhuma relação com os índices de mortalidade infantil, pois, mesmo nos países europeus, onde os índices de mortalidade são baixos, o número de jovens mortos vem crescendo. Em países considerados em desenvolvimento, como é o caso do Brasil, a taxa de homicídio de homens jovens é maior do que em países que passam por guerra civil ${ }^{33}$.

Esse fenômeno é reflexo do modelo de masculinidade que eles buscam viver e querer a todo custo provar que é "homem" forte, viril e poderoso. Eles buscam, por meio das facções criminosas, afirmar sua masculinidade utilizando-se da violência para amenizar os efeitos da exclusão social ${ }^{34}$. Assim, a falta de políticas públicas específicas para esse perfil etário, com suas idiossincrasias biopsicossociais, abre ainda mais espaço para o aliciamento de grupos com retóricas discursivas que prometem suprir as necessidades, ainda que os sujeitos precisem se valer de meios violentos e ilegais contra o Estado.

\footnotetext{
$29 \quad$ Adolescente 03,17 anos.

30 VOGLER, Christopher. A jornada do escritor: estruturas míticas para escritores. 2. ed. Tradução de Ana Maria Machado. Rio de Janeiro: Nova Fronteira, 2006. p. 58.

31 MARTÍN-BARÓ, Ignacio. Sistema, grupo y poder: psicología social desde centroamérica II. El Salvador: UCA Editores, 1989. p.168. Colección Textos Universitarios, v. 10.

32 No Brasil, considera-se jovem, de acordo com o Estatuto da Juventude, as pessoas que têm entre 15 e 29 anos de idade.

33 BARKER, Gary. Homens na linha de fogo: juventude, masculinidade e exclusão social. Tradução de Alexandre Arbex Valadares. Rio de Janeiro: 7Letras, 2008.

34 BARKER, Gary. Homens na linha de fogo: juventude, masculinidade e exclusão social. Tradução de Alexandre Arbex Valadares. Rio de Janeiro: 7Letras, 2008.
} 
Os debates sobre masculinidade vêm se intensificando. Há quem fale que estamos passando por uma crise de masculinidade, pois a identidade dos homens estaria sendo comprometida, tornando-se sem hegemonia $^{35}$. Não negamos que há, historicamente, uma diferença de direitos e deveres entre homens e mulheres, bem como é importante reconhecermos que a feminilidade é utilizada como parâmetro para medir o grau de masculinidade dos homens. Porém, não é nosso objetivo analisar a masculinidade a partir dessas configurações de gênero ou numa disputa binária ou comparativa como se um fosse fraco e o outro forte. Analisaremos a masculinidade enquanto representação de virilidade, uma demonstração de força e poder entre os adolescentes do sexo masculino, sem atribuir, com isso, às mulheres ou ao feminino o sentido de fraqueza, embora as facções deem esse tipo de significação machista, a ponto de pressionar os seus jovens membros a assumir estereótipos de "machos viris".

Apesar de haver um vasto entendimento do que seria a virilidade, não podemos analisar o ser viril dissociando-o das concepções de masculinidades, há um diálogo entre essas categorias. Em outras palavras, "é impossível falar de virilidade sem discutir a própria concepção de masculinidade"36.

A virilidade possui um duplo significado, podendo ser atribuída à noção de força, coragem, capacidade de lutar e dominar o outro, conforme será analisada aqui. A outra concepção, a qual não pretendemos adentrar, é a virilidade enquanto forma sexual erétil do homem e sua imposição de valores ${ }^{37}$.

As concepções de masculinidade não podem ser vistas de forma homogênea, já que elas mudam de acordo com as singularidades e histórias dos sujeitos ou grupos específicos. Isso é reflexo de uma construção social permeada por significados plurais e que tem por trás uma disputa de poder. É necessária uma compreensão das formações subjetivas dos adolescentes, relacionando-as à violência e à posse de arma de fogo que a construção social proporciona e as facções executam com esses sujeitos.

No contexto das facções criminosas, não vemos a virilidade como uma construção "naturalizada" da relação de subordinação homem-mulher, na forma historicamente posta, apesar de haver influências mútuas. Essas representações são afirmadas muito mais pela conjuntura de violência e poder de dominação do outro, que não é necessariamente uma mulher. Aliás, as mulheres não têm representatividade nos processos decisórios das facções, apesar haver indícios empíricos de aumento da sua participação ${ }^{38}$, mas as atividades por elas desempenhadas dentro do crime são vistas como secundárias, porque predomina uma questão de gênero muito forte, sendo vistas no espaço faccioso como uma "posse" dos presos. Prevalece, assim, a relação masculina entre homem-homem. A mulher fica, no máximo, entre os homens, o que torna uma relação homem-mulher-homem ${ }^{39}$.

Em regra, o papel desempenhado pelas mulheres emerge como uma espécie de prova de amor/poder para seu companheiro ou filho que se encontra custodiado. É caso, por exemplo, de ingressar nos ambientes prisionais portando drogas e/ou armas ou de servir como "aviãozinho 40 ". Logrando êxito na empreitada, ela e seu companheiro ganharão respeito dentro do grupo. As mulheres se tornaram peças-chave no interior das facções criminosas. Em alguns momentos são parceiras e desempenham papel importante dentro do cri-

35 SILVA, Sergio Gomes da. A crise da masculinidade: uma crítica à identidade de gênero e à literatura masculinista. Psicol. Cienc. Prof., Brasília, v. 26, n. 1, mar. 2006. Disponível em: http://pepsic.bvsalud.org/scielo.php?script=sci_arttext\&pid $=$ S1414-98932006000100011. Acesso em: 11 out. 2019.

36 VINUTO, Juliana; ABREO, Leandro de Oliveira; GONÇALVES, Hebe Signorini. No fio da navalha: efeitos da masculinidade e virilidade no trabalho de agentes socioeducativos. Plural, Revista do Programa de Pós-Graduação em Sociologia da USP, São Paulo, v. 24, n. 1, p. 61, 2017. Disponível em: http://www.revistas.usp.br/plural/article/view/126635. Acesso em: 13 dez. 2019.

37 VINUTO, Juliana; ABREO, Leandro de Oliveira; GONÇALVES, Hebe Signorini. No fio da navalha: efeitos da masculinidade e virilidade no trabalho de agentes socioeducativos. Plural, Revista do Programa de Pós-Graduação em Sociologia da USP, São Paulo, v. 24, n. 1, p. 54-77, 2017. Disponível em: http://www.revistas.usp.br/plural/article/view/126635. Acesso em: 13 dez. 2019.

38 PAIVA, Luiz Fábio S. "Aqui não tem gangue, tem facção": as transformações sociais do crime em Fortaleza, Brasil. Cadernos CRH, Salvador, v. 32, n. 85, p. 165-184, abr. 2019. Disponível em: http://www.scielo.br/pdf/ccrh/v32n85/0103-4979ccrh-32-85-0165.pdf. Acesso em: 26 out. 2019.

39 BIONDI, Karina. Junto e misturado: uma etnografia do PCC. São Paulo: Editora Terceiro Nome, 2017.

40 Refere-se às pessoas que fazem os mandados do crime, como a entrega de drogas, armas ou qualquer outra encomenda ilícita. 
me, em outros, são vítimas da violência entre os grupos, quando um acusa o outro de matar "mãezinhas" ${ }^{4142}$. Essa discussão foi enfrentada no livro "Prisioneiras". Ao investigar a realidade das mulheres presas no sistema carcerário, o autor percebeu que muitas delas eram esquecidas pelos seus familiares, apesar de muitas cumprirem pena por causa do companheiro ${ }^{43}$.

As masculinidades devem ser compreendidas a partir de um prisma hierárquico, considerando-se classes sociais, cor, orientação sexual ou ideologias facciosas. Diante disso, a virilidade dos sujeitos é um instrumento de poder, importante quando se busca disputar o controle do tráfico nas comunidades e domínio dos presídios/centros educacionais.

Não podemos esquecer que há uma masculinidade que se sobressai em relação a outras e acaba sendo utilizada como pressuposto para fundamentar as relações de poder. Assim, podemos falar de "masculinidades", no plural. As facções utilizam a masculinidade culturalmente reproduzida pelo Estado, presente nos órgãos de segurança pública. Os comportamentos dos sujeitos que participam das facções expressam bem essa realidade, pois eles se baseiam nas afirmações/imposições de masculinidade, força e poder do Estado para reproduzir tais conceitos, ora para se defender, ora para atacar. É o que acontece, por exemplo, quando os agentes de segurança são etiquetados como "homens" ou "zome". Isso demonstra uma afirmação hegemônica, mesmo que inconsciente, da masculinidade/virilidade e superpoderes da polícia, que acaba servindo de parâmetro para aquisição de armas e estratégias de guerra para agir contra seus inimigos.

A afirmação de masculinidade dos adolescentes, enquanto virilidade, é potencializada pelas facções criminosas. Elas dispõem de alternativas para suprir os desejos dos adolescentes que se encontram em estágio peculiar de desenvolvimento, especialmente, daqueles que estão em contextos de maior vulnerabilidade socioeconômica. Isso vai desde a distribuição de poderio bélico (armas para praticar assaltos, homicídios e "se defender dos inimigos") ao financeiro (tráfico de drogas e o incentivo à prática de atos infracionais contra o patrimônio). Eles são "desafiados e incentivados a agirem, sob pena de serem rotulados como 'fracos', 'bichas', 'moles', 'cagões', 'caretas', entre outros epítetos, a responderem a uma ofensa”"

No âmbito das facções criminosas, a masculinidade possui um viés bipolar. Tanto pode representar a conquista de poder sobre outro e ganhar respeito dentro da facção, quanto "um desvio em relação às normas de gênero pode resultar em ridículo ou em ser excluído de certos espaços”. Isso traz significados que interferem no comportamento dos adolescentes porque "definir a versão de masculinidade internalizada, projetada e vivida é uma questão de vida ou morte" ${ }^{35}$.

O privilégio que os adolescentes buscam, ao tentar afirmar sua masculinidade, por meio da violência, é algo intangível e virtual, porém real. Mas não como algo que eles possuem de modo estático. O que há são relações de poder, como visto anteriormente. Também não existe a possibilidade de domesticar os pares ou inimigos e torná-los propriedade. Ocorrem coalizões, para o bem ou para o mal. Diante disso, a virilidade ganha outra dimensão, pois "a virilidade [...] como aptidão ao combate e ao exercício da violência (sobretudo em caso de vingança), é, acima de tudo, uma carga" ${ }^{46}$.

41 PAIVA, Luiz Fábio S. “Aqui não tem gangue, tem facção”: as transformações sociais do crime em Fortaleza, Brasil. Cad. CRH, Salvador, v. 32, n. 85, p. 165-184, abr. 2019. Disponível em: http://www.scielo.br/pdf/ccrh/v32n85/0103-4979-ccrh-32-85-0165.pdf. Acesso em: 26 out. 2019.

42 Essa expressão pode ser vista, também, do ponto de vista da masculinidade, pois denota a ideia da "mulher-mãe" subalterna e cuidadora de filhos. Os filhos, nesse caso, não necessariamente são os filhos biológicos, mas aqueles que estão sob os cuidados das mulheres, como os membros das facções criminosas.

43 VARELLA, Drauzio. Prisioneiras. São Paulo: Companhia das Letras, 2017.

44 PIMENTA, Melissa de Mattos. Masculinidades e sociabilidades: Compreendendo o envolvimento de jovens com violência e criminalidade. Dilemas: Revista de Estudos de Conflitos e Controle Social, v. 7, n. 3, jul./ago./set. 2014. p. 714. Disponível em: https:// revistas.ufrj.br/index.php/dilemas/article/view/7239. Acesso em: 27 jun. 2019.

45 BARKER, Gary. Homens na linha de fogo: juventude, masculinidade e exclusão social. Tradução de Alexandre Arbex Valadares. Rio de Janeiro: 7Letras, 2008. p. 28.

46 BOURDIEU, Pierre. A dominação masculina. 11. ed. Tradução de Maria Helena Kühner. Rio de Janeiro: Bertrand Brasil, 2012. p. 64. 
Dentro das facções, há pressões para que os adolescentes ajam como "homem", tanto no que diz respeito ao tráfico de drogas, ao honrar com as regras de pagamento dos negócios, quanto o seu comportamento de gênero no sentido relacionado à sexualidade. Ao adolescente é imposta a concepção de "macho", no sentido de não ser afeminado, pois o feminino é visto como algo submisso, dependente e inferior.

Empiricamente, conseguimos perceber, a partir dos diálogos com adolescentes que cumprem medida socioeducativa de internação no CASE Mossoró, que o consumo de drogas e o porte de armas são vistos como ferramentas que potencializam a afirmação da masculinidade dentro das facções criminosas.

O consumo da maconha é utilizado para afirmar sua masculinidade e seu sentimento de coletividade, pois incentiva a união que, num ambiente de vulnerabilidades psíquicas, financeiras e sociais, serve como guia das relações dos grupos facciosos. Diante desse cenário,

[...] muitos adolescentes entram para as facções criminosas com o intuito de buscar poder, reconhecimento e respeito comunitário, conquistar as mulheres mais bonitas, ostentar com transporte, roupas e joias. Para conseguir isso, as facções dão amparo ${ }^{47}$.

Outro adolescente relata não consumir bebida alcoólica, porque ela o deixa em vulnerabilidade. Nas suas palavras, "não dou valor a beber, deixa o cara de vacilo"48. A negativa à bebida alcoólica se associa à noção de que os efeitos dela comprometem a autodefesa do sujeito contra os ataques dos seus inimigos, do Estado e das facções rivais.

Nesse ambiente, o consumismo, a busca por poder e a necessidade de pertencer a um grupo, associados à concepção de masculinidade, fazem os adolescentes se utilizarem da força para procurar adquirir respeito, disputar território e adquirir representatividade na comunidade. No mesmo sentido, isso se expressa de forma impositiva em busca de notoriedade social, demonstração de bravura e de ousadia, ao desafiar o Estado e combater as facções rivais. Portanto, para os sujeitos que fazem parte desses grupos, o "orgulho de ser homem não se origina na gentileza e outras disposições civilizadas, mas da capacidade e disposição de destruir o adversário" ${ }^{49}$.

Os conflitos entre os jovens variam de natureza, envolvendo territorialidade, torcidas organizadas, discussões político-partidárias e conflitos identitários de gênero. Os adolescentes compreendem a violência como um recurso eficaz na resolução de conflitos. Percebendo esse desejo dos adolescentes, as facções criminosas corroboram para que ocorram novos episódios de violências.

Hoje os adolescentes convivem com diferentes formas de sociabilidades, seja na escola, família ou nos espaços virtuais. Nessas relações sociais, está a violência dos centros urbanos, que representa grande ameaça para a vida dos jovens, sobretudo quando as facções criminosas despertam neles um sentimento de vizinhança, coleguismo e amizade, que competem por espaço de representatividade e diversão dentro da comunidade. Ao possibilitar o acesso a armas, veículos, aquisição exacerbada de produtos de "marca" e o consumo de drogas (esse último é visto como instrumento para se conquistar mulheres), as facções criminosas contribuem para que os adolescentes afirmem a masculinidade própria.

Porém, nem toda afirmação de masculinidade é carregada de violência física. É preciso analisar e refletir criticamente de que forma ela surge no meio social. A masculinidade fugiu da exclusividade binária "homem-mulher" para uma concepção a partir da história de vida social e cultural de cada sujeito. Devemos considerar que a masculinidade se expressa de diversas formas, apesar das facções quererem traçar um perfil de aceitação com níveis de masculinidades.

A masculinidade deve ser analisada dentro das concepções de gênero de cada sujeito. A violência física

\footnotetext{
47 Adolescente 01, 17 anos.

48 Adolescente 02,17 anos.

49 ZALUAR, Alba. Democratização inacabada: fracasso da segurança pública. Estudos avançados, Ano 21, n. 61, p. 31-49, 2007. p.46. Disponível em: http://jus2.scielo.br/pdf/ea/v21n61/a03v2161. Acesso em: 14 dez. 2019.
} 
contra mulheres é combatida dentro das facções, não sendo essa forma de se afirmar a masculinidade na relação com o sexo feminino, mas nem por isso ela não se expressa dentro dos grupos criminosos. Ela se manifesta noutra roupagem, principalmente com a noção de fertilidade, virilidade e com a conquista mulheres.

A concepção de fertilidade é vista pelos adolescentes como a capacidade de procriar, como é possível observarmos neste relato: "eu quero ser pai porque é massa" (ADOLESCENTE 03, 17 anos). Diante disso, como a maioria dos adolescentes não possuem bens materiais ou contribuição social digna de reconhecimento, uma das maneiras encontradas para deixar seu "legado" social e familiar é se tornar um genitor, ou seja, a busca por uma representação da semente humana. Isso muito se deve ao fato da diminuição das expectativas e projeções de vida desse segmento social.

A masculinidade não é afirmada de forma aleatória, há interesses escusos, não sendo diferente com as facções criminosas. Ela se expressa de acordo com regras de condutas que determinam e regulam a interação social entre os pares, em que busca respeitar a mão invisível que traz o "código de honra" de cada facção. Não se pode tomar decisão isolada dentro do grupo criminoso. Ninguém quer perder poder de decisão. É preciso decidir coletivamente para honrar e satisfazer o ego viril de cada sujeito pertencente ao coletivo. Essa concepção se coaduna com a de que "a virilidade tem que ser validada pelos outros homens, em sua verdade de violência real ou potencial, e atestada pelo reconhecimento de fazer parte de um grupo de 'verdadeiros homens" 50 .

Nos espaços onde estão presentes práticas ilícitas, há uma figura que merece destaque e deve ser compreendida a partir da virilidade e poder, e não propriamente da ideia de gênero. Essa figura é estereotipada como a "mulher de bandido". No binarismo de homem trabalhador e homem bandido, a mulher exerce forte influência na construção da identidade masculina. Ela, ao preferir o "homem bandido", em detrimento do trabalhador, empodera o "bandido" e o faz ganhar prestígio social.

Relacionar-se com "bandido de facção" dá uma (falsa) sensação de segurança e reconhecimento social. Percebemos que há uma "troca de favores" entre os sujeitos que praticam ilícitos e as mulheres que se envolvem com esses indivíduos. Eles oferecem poder econômico e respeito comunitário às mulheres. Em troca, eles procuram, no corpo delas, legitimar-se socialmente. Portanto, os homens preteridos pela sua condição de periférico passam a ver na influência que as facções exercem uma saída para conseguir relacionamentos amorosos com as mulheres mais "cobiçadas".

As facções são vistas como uma oportunidade para ascender socioeconomicamente, o que, muitas vezes, não se busca ou se desiste de atingir por meio de escassos e onerosos recursos lícitos. As práticas ilícitas são vistas pelos adolescentes como trabalho digno, pois, para quem vive em condições subumanas, os parâmetros de legalidade e legitimidade se tornam secundários, flexibilizados ou ressignificados a partir de outras bases não estatais.

A masculinidade também se faz presente nas palavras e nas coisas. A nomenclatura "irmão", utilizada para designar se um sujeito faz parte ou não da facção, entre outras noções, traz uma representação de virilidade que nos chama atenção. Para fazer parte, efetivamente, de uma facção, é necessário ter mais de 18 $\operatorname{anos}^{51}$, pois essa idade tem um simbolismo que carrega consigo a ideia de homem viril, capaz de se defender e atacar seus inimigos quando necessário. A virilidade é utilizada para distinguir hierarquicamente os membros das facções e a distribuição de tarefas durante os confrontos.

Os crimes sexuais também trazem representações importantes da masculinidade no ambiente faccioso. O código jurídico próprio das facções criminosas considera esse tipo de crime inaceitável. Os indivíduos

BOURDIEU, Pierre. A dominação masculina. 11. ed. Tradução de Maria Helena Kühner. Rio de Janeiro: Bertrand Brasil, 2012. p. 64.

51 Em pesquisa realizada em 2007, Karina Biondi assegurava que não era possível a participação de “menores” em facções criminosas. Eles seriam, no máximo, apoiadores do grupo, mas não podiam ser "batizados" (ritual que ratifica a entrada do sujeito nas facções). Por outro lado, Paiva (2019) menciona que a facção Guardiões do Estado (GDE) tem como uma das características o batismo de "menores". 
que cometerem ilícitos sexuais serão punidos de acordo com as regras das facções. Dentre outras regras, estão a humilhação e a violência, podendo ser decretada a expulsão e/ou a morte do "estuprador". Dito na linguagem deles, aqueles que praticam crimes sexuais são transformados em "mocinhas" da cadeia, o que representa uma mistura de poder e masculinidade, como artificial defesa do feminino ou da mulher. Com a violência sexual, busca-se equiparar os sujeitos violadores às mulheres, na vã concepção da inferioridade feminina, isso porque "a pior humilhação, para um homem, consiste em ser transformado em mulher" ${ }^{2}$. Em busca de conseguir maior coesão social e diminuir a violência no cárcere, há facções que aboliram o estupro de estupradores dentro das prisões (DIAS, 2013), acrescentando à retórica das facções termos do repertório estatal, um tipo de estratégia politicamente correta das organizações criminosas.

Outra forma de a masculinidade se manifestar dentro das facções é com o número de ilícitos praticados pelos "irmãos", pois quanto mais extenso for o "currículo criminal" do sujeito, mais representatividade e respeito ele possui dentro do mundo do crime. Quem não for capaz de demonstrar virilidade não será aceito nas facções ou passa a desempenhar um papel de pouca relevância, podendo cair no ostracismo, ser expulso ou morto. Isso porque "as manifestações (legítimas ou ilegítimas) da virilidade se situam na lógica da proeza, da exploração, do que traz honra ${ }^{53}$ ".

Dentro do CASE, a masculinidade é colocada à prova quando os adolescentes se utilizam da violência para afirmar sua identidade facciosa perante os adolescentes rivais ou contra os agentes do Estado. A prática viril, ao passo que dá uma sensação de poder, também produz receio nos membros hierarquicamente inferiores e nos membros das facções rivais, já que, além do poderio financeiro, o outro fator que potencializa a subida hierárquica dos membros é a crueldade nos atos praticados. Nesse sentido, há um discurso: "para subir na hierarquia precisa ter muito dinheiro, muitos homicídios, muito conhecimento e experiência. Se possível, ser formado no crime e na faculdade [graduação]" 54 .

Portanto, almejar ascensão social é um atributo que representa a afirmação de poder e identidade masculina dentro da comunidade. Isso não propicia apenas o acesso a bens consumo, como também prestígio perante seus pares. $\mathrm{O}$ respeito que os adolescentes buscam está calcado nos indicadores de independência econômica, associados a uma hegemonia de identidade, poder e virilidade masculina ${ }^{55}$. As facções criminosas constituem terreno fértil para os adolescentes buscarem (re)significar sua concepção de poder e sua masculinidade em troca de reconhecimento social.

\section{Considerações finais}

Num cenário em que buscamos estratégias para conter a prática de atos infracionais e reduzir a participação de adolescentes em facções criminosas, analisamos, a partir de uma abordagem teórica e empírica, a masculinidade e a vontade de poder desses sujeitos que se encontram em estágio peculiar de desenvolvimento biopsicossocial, especialmente pensando nos jovens de comunidades mais empobrecidas materialmente, aos quais se somam vulnerabilidades socioeconômicas.

Diante disso, acreditamos que o poder e a masculinidade dos adolescentes não podem ser vistos de forma dissociada porque se comunicam. Um subsidia o outro. Para os adolescentes, o poder se expressa

\footnotetext{
52 BOURDIEU, Pierre. A dominação masculina. 11. ed. Tradução de Maria Helena Kühner. Rio de Janeiro: Bertrand Brasil, 2012. p. 32.

53 BOURDIEU, Pierre. A dominação masculina. 11. ed. Tradução de Maria Helena Kühner. Rio de Janeiro: Bertrand Brasil, 2012. p. 29.

54 Adolescente 01,17 anos.

55 TAVARES, Rosana Carneiro. O Sentimento de Pertencimento Social como um Direito Universal. Cad. de Pesq. Interdisc. em Ci-s. Hum-s., Florianópolis, v.15, n. 106, p. 179-201, jan./jun. 2014. Disponível em: https://periodicos.ufsc.br/index.php/cadernosdepesquisa/article/view/19848951.2014v15n106p179. Acesso em: 28 jun. 2019.
} 
de várias formas, seja na utilização de armas de fogo, na inserção no tráfico de drogas e na prática de atos contra o patrimônio, entre outras, como meio de obter ascensão social e reconhecimento.

O acesso a essas atividades ilícitas funciona como meio para os adolescentes afirmarem sua masculinidade e se sobressaírem em meio às relações de poder. Esses sujeitos se utilizam da capacidade financeira que os atos infracionais e a participação em facções criminosas lhes proporcionam para namorar as "novinhas" mais cobiçadas da "balada". Além disso, a prática de atos ilícitos ordenados pelas facções criminosas demonstra habilidades especiais. Assim, um bom "currículo" proporciona visibilidade dentro do grupo. Eles passam a ser vistos como pessoas viris, algo capaz de alçá-los à condição de herói ou "guerreiro".

Portanto, o poder e a masculinidade dos adolescentes se expressam em conjunturas de práticas infracionais e na participação em facções criminosas e constituem instrumentos que dinamizam o reconhecimento social dessas pessoas nas suas comunidades, nos centros de atendimento socioeducativo e nas facções criminosas.

\section{Referências}

AMORIN, Carlos. CV-PCC: a irmandade do crime. Rio de Janeiro: Record, 2003.

ARENDT, Hannah. Da violência. Brasília: Ed. Universidade de Brasília, 1985.

BARKER, Gary. Homens na linha de fogo: juventude, masculinidade e exclusão social. Tradução de Alexandre Arbex Valadares. Rio de Janeiro: 7Letras, 2008.

BIONDI, Karina. Junto e misturado: uma etnografia do PCC. São Paulo: Terceiro Nome, 2017.

BIONDI, Karina. Relações políticas e termos criminosos: o PCC e uma teoria do irmão-rede. Teoria \& sociedade, Belo Horizonte, v. 15, n. 2, p. 206-235, 2007. Disponível em: https://neip.info/novo/wp-content/ uploads/2017/03/Biondi_PCC_Teoria_Irm\%C3\%A3o-Rede_Sociedade_2007.pdf. Acesso em: 30 out. 2019.

BOURDIEU, Pierre. A dominação masculina. 11 ed. Tradução de Maria Helena Kühner. Rio de Janeiro: Bertrand Brasil, 2012.

BRASIL. Lei $n^{0}$ 12. 852/2013. Institui o Estatuto da Juventude e dispõe sobre os direitos dos jovens, os princípios e diretrizes das políticas públicas de juventude e o Sistema Nacional de Juventude - SINAJUVE. Diário Oficial [da] República Federativa do Brasil, Brasilia, DF, 6 ago. 2013.

DIAS, Camila Caldeira Nunes. PCC: hegemonia nas prisões e monopólio da violência. São Paulo: Saraiva, 2013.

FELTRAN, Gabriel Santis. Crime e castigo na cidade: os repertórios da justiça e a questão do homicídio nas periferias de São Paulo. Caderno CRH, Salvador, v. 23, n. 58, p. 59-73, Jan./Abr. 2010. Disponível em: http:// www.scielo.br/pdf/ccrh/v23n58/v23n58a05.pdf. Acesso em: 05 mar. 2020.

FOUCAULT, Michel. Microfísica do Poder. Organização e tradução de Roberto Machado. 18 ed. Rio de Janeiro: Edições Graal, 1979.

FOUCAULT, Michel. O sujeito e o poder. In: DREYFUS, L.; RABINOW, P. Michel Foucault: uma trajetória filosófica: para além do estruturalismo e da hermenêutica. 2. ed. Rio de Janeiro: Forense Universitária, 2009. p. 231-249.

FOUCAULT, Michel. Vigiar e punir: nascimento da prisão; tradução de Raquel Ramalhete.42. ed. Petrópolis, RJ: Vozes, 2014. 
Lima, Renata Mantovani de; POLI, Leonardo Macedo; JOSÉ, Fernanda São. A Evolução Histórica dos Direitos da Criança e do Adolescente: da insignificância jurídica e social ao reconhecimento de direitos e garantias fundamentais. Rev. Bras. Polít. Públicas (Online), Brasília, v. 7, n. 2, p. 313-329, 2017. Disponível em:https://www.publicacoesacademicas.uniceub.br/RBPP/article/view/4796/pdf. Acesso em: 05 mar. 2020.

MANSO, Bruno Paes; DIAS, Camila Nunes. A guerra: a ascensão do PCC e o mundo do crime no Brasil. 1. ed. São Paulo: Todavia, 2018.

MARINO FILHO, Armando. A Necessidade da Educação do Poder e do Domínio para as Relações Sociais e Políticas. Rev. Psicol. Polít., São Paulo, v. 10 n. 20, dez. 2010. Disponível em: http://pepsic.bvsalud.org/ scielo.php?script=sci_arttext\&pid=S1519-549X2010000200006. Acesso em: 12 set. 2019.

MARTÍN-BARÓ, Ignacio. Sistema, grupo y poder: psicología social desde centroamérica II. El Salvador: UCA Editores, 1989. Colección Textos Universitarios, v. 10.

OLIVEIRA, Ramon Rebouças Nolasco de; NOGUEIRA, Jailson Alves. O Intrincamento entre os Códigos Jurídicos do Estado de Direito e das Facções Criminosas. Meritum, Belo Horizonte, v. 14, n. 1, p. 413-428, jan./jun. 2019. Disponível em: http://www.fumec.br/revistas/meritum/article/view/6592/pdf. Acesso em: 06 out. 2019.

PAIVA, Luiz Fábio S.. "Aqui não tem gangue, tem facção”: as transformações sociais do crime em Fortaleza, Brasil. Cadernos CRH, Salvador, v. 32, n. 85, p. 165-184, abr. 2019. Disponível em: http://www.scielo.br/ pdf/ccrh/v32n85/0103-4979-ccrh-32-85-0165.pdf. Acesso em: 26 out. 2019.

PIMENTA, Melissa de Mattos. Masculinidades e sociabilidades: Compreendendo o envolvimento de jovens com violência e criminalidade. Dilemas: Revista de Estudos de Conflitos e Controle Social, v. 7, n. 3, p. 701730, jul./ago./set. 2014. Disponível em: https://revistas.ufrj.br/index.php/dilemas/article/view/7239. Acesso em: 27 jun. 2019.

SANTIN, Janaína Rigo; MARCANTE, Sheron. Microfísica do poder e poder local. Revista Brasileira de História \& Ciências Sociais, v. 6, n. 11, jul. 2014. Disponível em: https://www.rbhcs.com/rbhcs/article/ view/207. Acesso em: 27 nov. 2019.

SILVA, Barbara Letícia Gomes da; SOUSA, Maria Júlia Costa Leite e. Comando vermelho e primeiro comando da capital: o fenômeno das facções criminosas brasileiras à luz do pluralismo jurídico e da sociologia weberiana. 2018 (no prelo).

SILVA, Sergio Gomes da. A crise da masculinidade: uma crítica à identidade de gênero e à literatura masculinista. Psicol. Cienc. Prof., Brasília, v. 26, n. 1, mar. 2006. Disponível em: http://pepsic.bvsalud.org/scielo. php?script=sci_arttext\&pid=S1414-98932006000100011. Acesso em: 11 out. 2019.

SUPOSTA facção criminosa promete punir bandidos em Santa Cruz. Agora RN. Disponível em: http:// agorarn.com.br/regionais/suposta-faccao-criminosa-promete-punir-bandidos-em-santa-cruz/. Acesso em: 20 jul. 2019.

TAVARES, Rosana Carneiro. O Sentimento de Pertencimento Social como um Direito Universal. Cad. de Pesq. Interdisc. em Ci-s. Hum-s., Florianópolis, v.15, n. 106, p. 179-201, jan./jun. 2014. Disponível em: https:// periodicos.ufsc.br/index.php/cadernosdepesquisa/article/view/19848951.2014v15n106p179. Acesso em: 28 jun. 2019.

TRÁFICO espalha cartazes anunciando queda no preço do botijão de gás na rocinha. Extra. Disponível em: https://extra.globo.com/casos-de-policia/trafico-espalha-cartazes-anunciando-queda-no-preco-dobotijao-de-gas-na-rocinha-21893233.html. Acesso em: 28 nov. 2019.

VARELLA, Drauzio. Prisioneiras. São Paulo: Companhia das Letras, 2017. 
VINUTO, Juliana; ABREO, Leandro de Oliveira; GONÇALVES, Hebe Signorini. No fio da navalha: efeitos da masculinidade e virilidade no trabalho de agentes socioeducativos. Plural, Revista do Programa de Pós-Graduação em Sociologia da USP, São Paulo, v.24, n.1, p. 54-77, 2017. Disponível em: http://www. revistas.usp.br/plural/article/view/126635. Acesso em: 13 dez. 2019.

VOGLER, Christopher. A jornada do escritor: estruturas míticas para escritores. 2. ed. Tradução de Ana Maria Machado. Rio de Janeiro: Nova Fronteira, 2006.

ZALUAR, Alba. Democratização inacabada: fracasso da segurança pública. Estudos avançados, ano 21, n. 61, p. 31-49, 2007. Disponível em: http://jus2.scielo.br/pdf/ea/v21n61/a03v2161. Acesso em: 14 dez. 2019. 
Para publicar na revista Brasileira de Políticas Públicas, acesse o endereço eletrônico www.rbpp.uniceub.br

Observe as normas de publicação, para facilitar e agilizar o trabalho de edição. 